Article

\title{
Organic Ion-Associate Phase Microextraction/Back-Microextraction for Preconcentration: Determination of Nickel in Environmental Water Using 2-Thenoyltrifluoroacetone via GF-AAS
}

\author{
Mitsuhito Kosugi, Kenta Mizuna, Kazuto Sazawa, Takuya Okazaki, Hideki Kuramitz (D, Shigeru Taguchi \\ and Noriko Hata *
}

check for updates

Citation: Kosugi, M.; Mizuna, K.; Sazawa, K.; Okazaki, T.; Kuramitz, H.; Taguchi, S.; Hata, N. Organic Ion-Associate Phase

Microextraction/Back-

Microextraction for Preconcentration:

Determination of Nickel in

Environmental Water Using 2-Thenoyltrifluoroacetone via GF-AAS. AppliedChem 2021, 1, 130-141. https://doi.org/10.3390/ appliedchem 1020010

Academic Editor: Jason Love

Received: 15 October 2021

Accepted: 23 November 2021

Published: 1 December 2021

Publisher's Note: MDPI stays neutral with regard to jurisdictional claims in published maps and institutional affiliations.

Copyright: (c) 2021 by the authors. Licensee MDPI, Basel, Switzerland. This article is an open access article distributed under the terms and conditions of the Creative Commons Attribution (CC BY) license (https:/ / creativecommons.org/licenses/by/ $4.0 /)$.
Department of Environmental Biology and Chemistry, Graduate School of Science and Engineering, University of Toyama, 3190 Gofuku, Toyama 930-8555, Japan; kosukun2222@yahoo.co.jp (M.K.); nananana_ranran@yahoo.co.jp (K.M.); sazawa@sci.u-toyama.ac.jp (K.S.); okazaki@meiji.ac.jp (T.O.); kuramitz@sci.u-toyama.ac.jp (H.K.); crewoftaguchiut@gmail.com (S.T.)

* Correspondence: hata1000ko@gmail.com

Abstract: An ion-associate phase (IAP) microextraction/ back-microextraction system was applied for the enrichment, separation, and detection of trace amounts of nickel from environmental water samples. Thenoyltrifluoroacetone (HTTA) acted not only as a chelating reagent for nickel, but also as a component of the extraction phase, i.e., IAP. Nickel in a $40 \mathrm{~mL}$ sample solution was pH-adjusted with phenolsulfonate ( $\mathrm{PS}^{-}$) and tetramethylammonium hydroxide and converted by chelation reaction in the presence of thenoyltrifluoroacetonate $\left(\mathrm{TTA}^{-}\right)$. When benzyldodecyldimethylammonium ion $\left(\mathrm{C}_{12} \mathrm{BzDMA}^{+}\right)$was added, a suspension of IAP formed in the solution. The IAP consisted of TTA ${ }^{-}$, a chelating reagent, the $\mathrm{PS}^{-}$, a component of $\mathrm{pH}$ buffer, and $\mathrm{C}_{12} \mathrm{BzDMA}^{+}$, which helps extract the chelating complex. When the solution was centrifuged, the IAP separated from the suspension and the nickel-TTA chelate was extracted into the bottom phase of the centrifuge tube. After the aqueous phase was taken away, $100 \mu \mathrm{L}$ of nitric acid (2 M) solution containing phosphate was used to back-microextract nickel from the IAP. The acid phase was measured via graphite-furnace atomic-absorption spectrometry (GF-AAS). The proposed method facilitated a 400-fold enrichment. The limit of detection was $0.02 \mu \mathrm{g} \mathrm{L}^{-1}$. The proposed method was applied for the determination of nickel in river water and seawater samples.

Keywords: ion-associate phase microextraction; back-microextraction; nickel; river water; seawater; 2-thenoyltrifluoroacetone; $\beta$-diketones; GF-AAS

\section{Introduction}

Nickel is ubiquitous in our daily live s and is also found in trace amounts in environmental water [1]. According to the WHO guidelines, the nickel concentration of drinking water should be $0.07 \mathrm{mg} / \mathrm{L}$. The International Agency for Research on Cancer concluded that inhaled nickel compounds are carcinogenic to humans (Group 1) [2]. Nickel is used in a wide range of compounds, including stainless steel and nickel alloys [2]. Moreover, nickel is used in nickel-cadmium and nickel-metal hydride batteries as well as lithium-ion batteries. These batteries are used in electric vehicles and their demand is expected to rise with their widespread use in the future [3]. However, nickel contamination due to the increased use of batteries causes aquatic environment pollution; therefore, it is necessary to collect the baseline data of nickel that exists in the environment.

Graphite-furnace atomic-absorption spectrometry (GF-AAS) has high sensitivity and requires only a small sample volume of $10-20 \mu \mathrm{L}$. Although the sensitivity of GF-AAS is high enough to allow the detection of trace elements at low concentrations, thus allowing adherence to $\mathrm{WHO}$ guidelines, it is still low for detecting the presence of trace elements 
in environmental water such as river water and seawater. Similar to other atomic spectroscopic methods, GF-AAS is affected by coexisting components; thus, pretreatment, such as extraction, enrichment, and separation, is necessary.

Enrichment and separation techniques that require low sample volume include liquidliquid extraction/back-microextractions [4], cloud point extractions [5-7], dispersive liquidliquid extractions [7-9], thermoresponsive polymer-mediated extractions [10,11], and homogeneous liquid-liquid extractions [12-14]. The efficiency of these techniques depends on application of heat $[5,6,11,13]$, use of chlorobenzene, chloroform, or xylene as an extractant [4,7-9]; and use of a fluorinated surfactant [12] or dry ice [14]. Herein, we propose an ion-associate phase (IAP) extraction technique $[15,16]$ that improves sensitivity and removes interfering components, and use it as a pretreatment technique for atomic spectroscopy [17-20]. Through the proposed method, the analyte in environmental water can be converted to moderate hydrophobicity as needed, and an organic cation $\left(\mathrm{Q}^{+}\right)$and an organic anion $\left(\mathrm{OA}^{-}\right)$can be added to form an ion associate. Centrifugation separates the IAP and removes the aqueous phase. The IAP is dissolved in a watermiscible solvent (2-methoxyethanol) [17] or a mixture of methanol and nitric acid [18], or is back-microextracted with nitric acid $[19,20]$, and the analyte is characterized through atomic spectroscopy.

As a chelating reagent of heavy metals for IAP extraction, a 2-(5-bromo-2-pyridylazo)5-(N-propyl-N-sulfopropylamino)phenol (5-Br-PAPS) is typically used [17-19], which is expensive. As chelating reagent of lithium for IAP extraction, a dipivaloylmethane (HDPM) is used [20]. HDPM not only reacts selectively with lithium to form a chelating complex, but also acts as an $\mathrm{OA}^{-}$for the proposed IAP extraction/back-microextraction [20]; it is also inexpensive. Moreover, $\beta$-diketones are chosen as chelating reagents of heavy metals for IAP extraction, because they can also act as $\mathrm{OA}^{-}$, which are the component of the IAP. Thenoyltrifluoroacetone (HTTA), a hydrophobic chelating agent, a type of $\beta$-diketones, serves as the $\mathrm{OA}^{-}$in the developed IAP microextraction. The combined use of IAP microextraction and back-microextraction facilitates the beneficial integration of preconcentration and GF-AAS for nickel detection. To verify the applicability of the proposed method, we used it to measure the nickel concentration in river and seawater samples through GF-AAS.

\section{Experimental}

\subsection{Reagents and Chemicals}

The standard solution of nickel, $1000 \mathrm{mg} \mathrm{L}^{-1}$, was prepared by dissolving nickel(II) nitrate hexahydrate (99.9\%, Wako Pure Chemical, Osaka, Japan) in $0.1 \mathrm{M}$ nitric acid. HTTA solution was prepared by dissolving HTTA (99\%, Aldrich, St. Louis, MO, USA) in acetone to make 0.1 M. Benzoylacetone (BzA) solution was prepared by dissolving BzA (1-phenyl1,3-butanedione, Wako Pure Chemical, Osaka, Japan) in acetone to make 0.1 M. A phenolsulfonate $\left(\mathrm{PS}^{-}\right.$) solution was prepared by dissolving sodium 4-hydroxybenzenesulfonate (Tokyo Chemical Industry, Tokyo, Japan) in water to make $0.5 \mathrm{M}$, and then purified. For purification, a 0.1\% 1-(2-pyridylazo) 2-naphthol (PAN) ethanol solution was added to the $\mathrm{PS}^{-}$solution and the $\mathrm{pH}$ was adjusted to 9 to form a PAN complex, which was then filtered off. This was repeated again and the $\mathrm{PS}^{-}$solution was used. A tetramethylammonium hyhdroxide (TMAH) was diluted a TMAH solution (25\%, AA-grade, Tama Chemicals, Kawasaki, Japan) to $12.5 \%$ with water. $\mathrm{Q}^{+}$solutions were prepared as follows. The bromide of benzyldodecyldimethylammonium $\left(\mathrm{C}_{12} \mathrm{BzDMA}^{+}\right)$, chlorides of benzyldimethyltetradecylammonium $\left(\mathrm{C}_{14} \mathrm{BzDMA}^{+}\right)$, and benzethonium $\left(\mathrm{Ben}^{+}\right)$, were dissolved in water to make $0.1 \mathrm{M}$. A nitric acid solution for back-microextraction, was prepared by dissolving $0.5 \mathrm{~g}$ of ammonium dihydrogen phosphate in $100 \mathrm{~mL}$ of $2 \mathrm{M}$ nitric acid.

All other reagents (e.g., nitric acid, acetone, ethanol, methanol, 2-methoxyethanol) were of analytical grade and were used as received. An ultrapure water with a specific resistance of 18.2 M $\Omega \mathrm{cm}$ (Direct-Q3 UV system, Millipore, Tokyo, Japan) was used throughout. 


\subsection{Apparatus}

Trace nickel in the aqueous solutions was measured using a Hitachi (Tokyo, Japan) Z-8000 GF-AAS. The instrumental conditions for GF-AAS were an analytical wavelength of $232.0 \mathrm{~nm}$, a sample volume of $10 \mu \mathrm{L}$, and a slit of $0.4 \mathrm{~nm}$.

For centrifugation, Kubota (Type 5420, Tokyo, Japan) and Kokusan (Type H-80R, Saitama, Japan) centrifuges were used.

The measurement of the UV spectra was performed with a Hitachi (Tokyo, Japan) Model U-2000A, and a Shimadzu (Kyoto, Japan) Model UV-2450 spectrophotometers (1 cm quartz cell).

Mixing and shaking of samples for back-microextraction was performed using Taitec (Koshigaya, Japan) test tube mixer (Present Mixer).

A $50 \mathrm{~mL}$ plastic centrifuge tube (Violamo, AS ONE, Osaka, Japan) with a centrifugal strength of $20,000 \mathrm{G}$ was used during the entire sample preparation process. A glass centrifuge tube was used to measure the UV absorption spectrum.

\section{Results and Discussion}

\subsection{Chelate Complex Formation}

As chelating reagents for the extraction of nickel from water, dithiocarbamates [4,9], 2-(5-bromo-2-pyridylazo)-5-dimethylaminoaniline [6], PAN [7,8,21], 8-quinolinol [10], and 5 -Br-PAPS [19] have been used apart from $\beta$-diketones, such as HTTA [22-25].

HTTA and benzoylacetone (BzA) were used as chelating reagents because they make stable complexes with nickel and are $\beta$-diketones [26], which are a constituent of the IAP and an $\mathrm{OA}^{-}$. The acid dissociation constant, $\mathrm{p} K_{\mathrm{a}}$, of HTTA is 6.2 [27], and of BzA is 8.88 [27]. The effect of $\mathrm{pH}$ on the complexation of the $\beta$-diketones chelating reagent HA (HTTA or BzA) with nickel was investigated. Here, $\mathrm{pH}$ was adjusted using phenol sulphonate and TMAH solutions. The effect of $\mathrm{pH}$ on the formation of nickel chelate complexes when HTTA and BzA are used as chelating reagents is shown in Figure 1. The recoveries of both HTTA and BzA decrease with increasing acidity or basicity. $\beta$-Diketones cannot be coordinated in metals unless they are deprotonated to the enol form [26]. However, when the $\mathrm{pH}$ is too high, hydroxide complexes are formed, and the formation of $\beta$-diketonate complexes is considered to be inhibited. In this study, HTTA was selected because the recovery for HTTA is higher than that for BzA at the optimum $\mathrm{pH}$. $\mathrm{pH} 8$ was chosen as the optimal $\mathrm{pH}$ because at this value, the highest recovery was achieved. At $\mathrm{pH} 8$, calculations at $\mathrm{p} K_{\mathrm{a}}=6.2$ [27] show that this chelating reagent exists mostly as an anion, $\mathrm{TTA}^{-}$.

HTTA is soluble in water only at $0.02 \mathrm{~g}$ per $100 \mathrm{~mL}$ [26]. The organic solvents used to dissolve and prepare HTTA, namely, acetone, methanol, ethanol, and 2-methoxyethanol, were investigated for their effect on the determination of nickel. As a solvent for preparing HTTA, acetone recovered nickel almost quantitatively, while methanol and ethanol recovered about $80 \%$ and 2-methoxyethanol about $50 \% \mathrm{Ni}$. Thus, in this study, acetone was selected.

The recovery was determined using double extraction. The recovery $(\mathrm{R})$ is:

$$
\mathrm{R} \%=\left(C_{1}-C_{2}\right) / C_{1} \times 100
$$

where $C_{1}$ is the concentration of nickel or absorbance at $232 \mathrm{~nm}$ during the first extraction into $100 \mu \mathrm{L}$ of nitric acid solution and $C_{2}$ is the concentration of nickel or absorbance at $232 \mathrm{~nm}$ during the second extraction into $100 \mu \mathrm{L}$ of nitric acid solution.

When water was added to the acetone solution of HTTA to reduce the volatilisation of acetone, the nickel recovery was decreased. Thus, in this study, the HTTA acetone solution was stored and used as is without diluting it with water.

The Ni-TTA complex was formed and extracted quantitatively in to the IAP at $\mathrm{pH} 8$. For increasing the $\mathrm{pH}$ value from $0.01 \mathrm{M}$ nitric acid solution (about $\mathrm{pH}$ 2) to $\mathrm{pH} 8$ acidity, four different $\mathrm{pH}$ buffers and $\mathrm{pH}$ adjusters, (1) a mixture of tris(hydroxymethyl)aminomethane (Tris) $\left(\mathrm{p} K_{\mathrm{a} 2}=8.20\right)$ [27], hydrochloric acid and disodium carbonate, (2) potassium hy- 
droxide, (3) disodium carbonate, (4) a mixture of phenolsulfonate $\left(\mathrm{p} K_{\mathrm{a} 2}=8.56\right)$ [27] and tetramethylammonium hydroxide (TMAH) were used for complex formation and their effect on the preconcentration and determination of nickel was investigated. For $\mathrm{pH}$ adjustment, a mixture of phenolsulfonate and tetramethylammonium hydroxide (TMAH) was recommended because it afforded a quantitative recovery of nickel. The phenolsulfonate ion $\left(\mathrm{PS}^{-}\right)$is not only a component of $\mathrm{pH}$ buffers, but also one of the $\mathrm{OA}^{-}$that constitute IAP.

The reaction of nickel with $\mathrm{TTA}^{-}$in a solution of $\mathrm{pH} 8$ follows Equations (2)-(4).

$$
\begin{gathered}
\mathrm{HTTA}+\mathrm{OH}^{-} \rightleftharpoons \mathrm{TTA}^{-}+\mathrm{H}_{2} \mathrm{O} \\
\mathrm{Ni}^{2+}+2 \mathrm{TTA}^{-} \rightleftharpoons \mathrm{Ni}(\mathrm{TTA})_{2} \\
\mathrm{Ni}^{2+}+3 \mathrm{TTA}^{-} \rightleftharpoons\left[\mathrm{Ni}(\mathrm{TTA})_{3}\right]^{-}
\end{gathered}
$$

The optimal amount of the chelating reagent HTTA for nickel was investigated (Figure 2). The amount of the HTTA acetone solution added was changed from 0.25 to $2.0 \mathrm{~mL}$. The highest recovery was observed at $0.5 \mathrm{~mL}$, and under these experimental conditions, TTA was present tens of thousands of times more moles than nickel. The decrease in recovery with increasing amounts of the HTTA acetone may be due to the slight solubilisation of the IAP in the presence of acetone. Thus, in this study, the addition of $0.5 \mathrm{~mL}$ HTTA acetone solution was recommended.

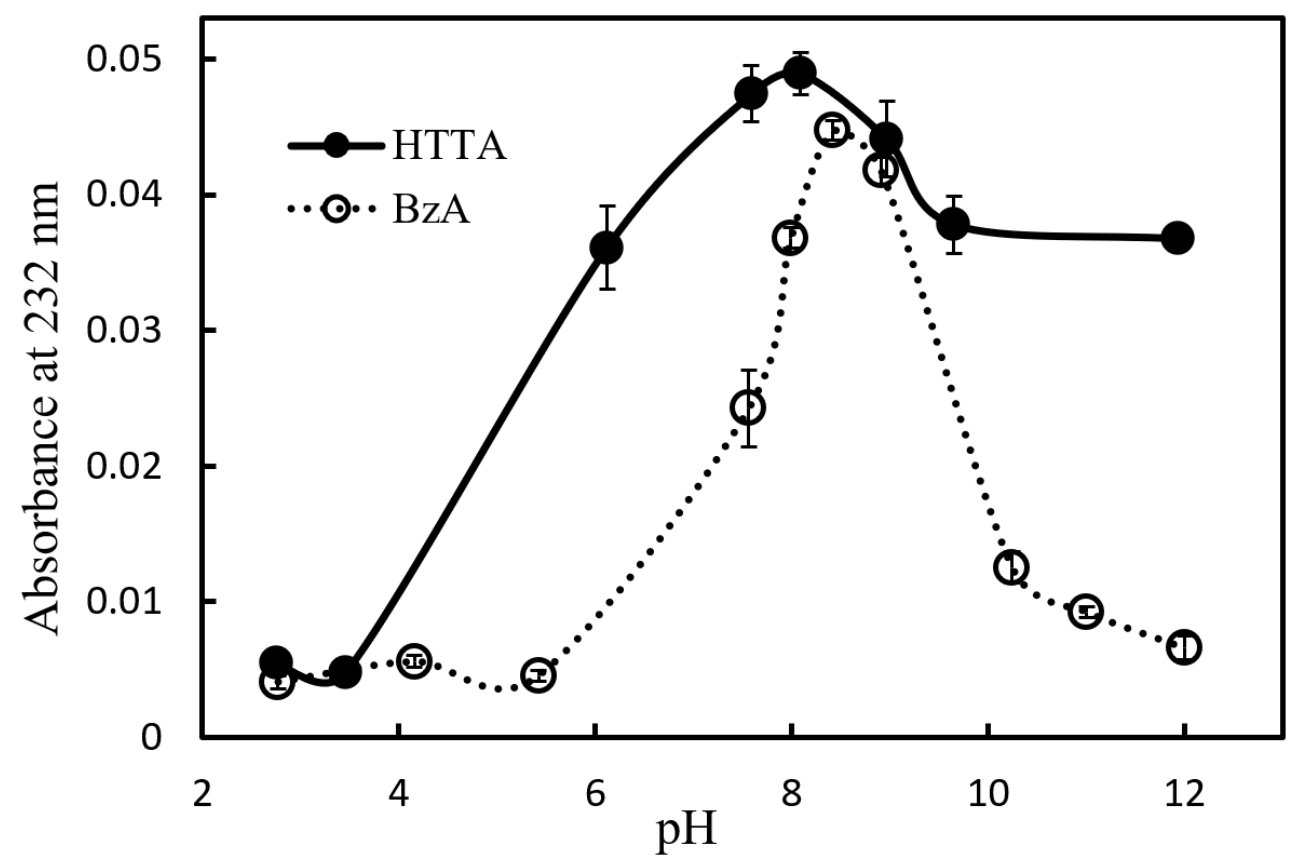

Figure 1. Effect of $\mathrm{pH}$ on chelate formation of nickel for different chelating reagents. Black circle: 2-thenoyltrifluoroacetone (HTTA), white circle: benzoylacetone (BzA), concentration factor; 400, $\left[\mathrm{Ni}^{2+}\right] ; 1.0 \mu \mathrm{g} \mathrm{L}{ }^{-1}$.

\subsection{Ion-Associate Phase (IAP) Microextraction}

At $\mathrm{pH} 8$, where $\mathrm{Ni}$ is extracted into IAP, from the $\mathrm{p} K_{\mathrm{a}}$ value, thenoyltrifluoroacetone is mostly $(98 \%)$ present as $\mathrm{TTA}^{-}$, $\mathrm{pH}$ buffer component is about $80 \%$ as $\mathrm{PS}^{-}$and the remaining $20 \%$ as $\mathrm{PS}^{2-}$. In the proposed IAP microextraction method, $\mathrm{TTA}^{-}$(the chelating reagent) and $\mathrm{PS}^{-}$(the component of the $\mathrm{pH}$ buffer) act as the constituent ions $\left(\mathrm{OA}^{-}\right)$of the IAP. When $\mathrm{Q}^{+}$is added, the IAP is formed. Therefore, the number of different reagents to be added can be reduced. The $\mathrm{C}_{12} \mathrm{BzDMA}^{+}, \mathrm{C}_{14} \mathrm{BzDMA}^{+}$, and Ben ${ }^{+}$were investigated as possible $\mathrm{Q}^{+}$constituents of the IAP (Figure 3 ). $\mathrm{C}_{12} \mathrm{BzDMA}^{+}$was chosen as the $\mathrm{Q}^{+}$because of the recovery of nickel was highest for $\mathrm{C}_{12} \mathrm{BzDMA}^{+}$. 


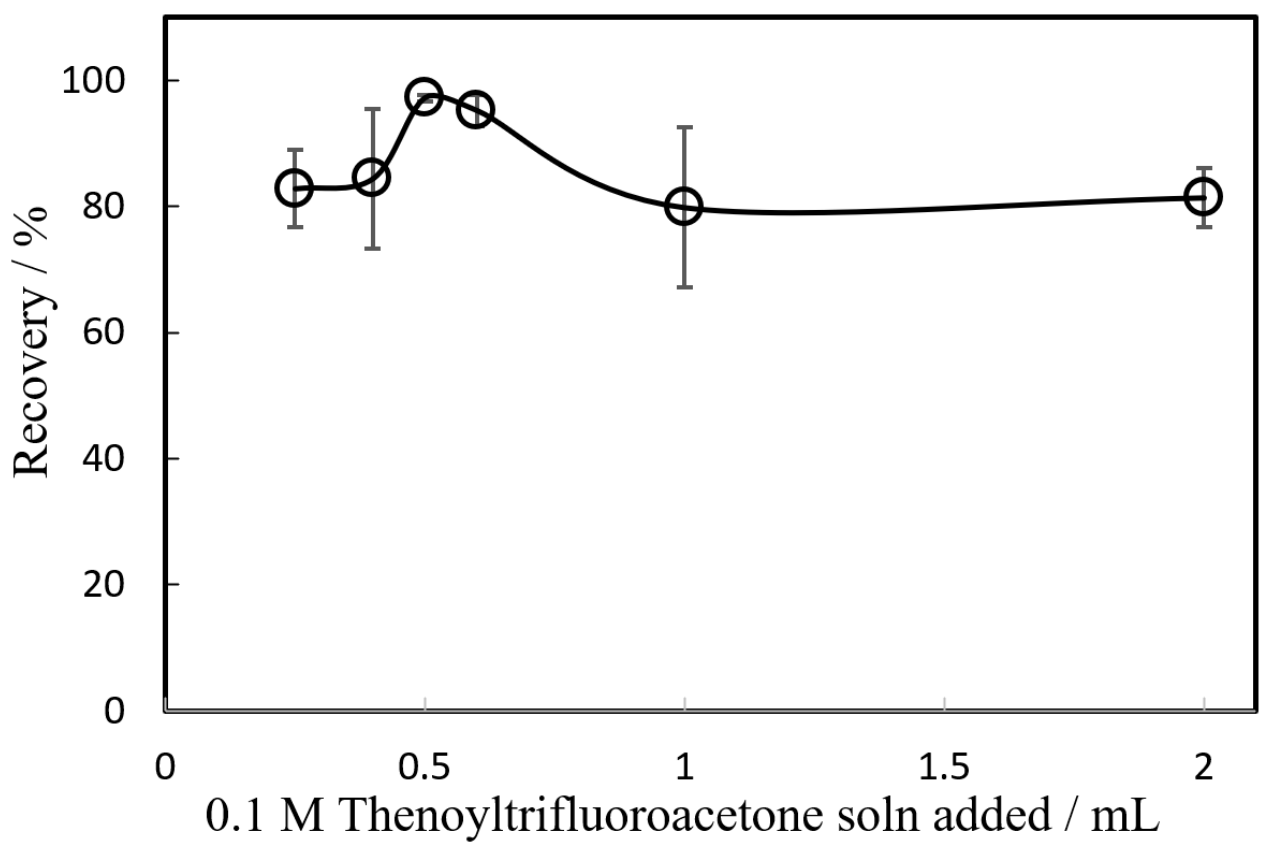

Figure 2. Effect of the amount of the HTTA acetone solution added on chelate formation of nickel and ion-associate phase (IAP) formation to determine through graphite-furnace atomic-absorption spectrometry (GF-AAS) for nickel, concentration factor; $400,\left[\mathrm{Ni}^{2+}\right] ; 1.0 \mu \mathrm{g} \mathrm{L}^{-1}$.

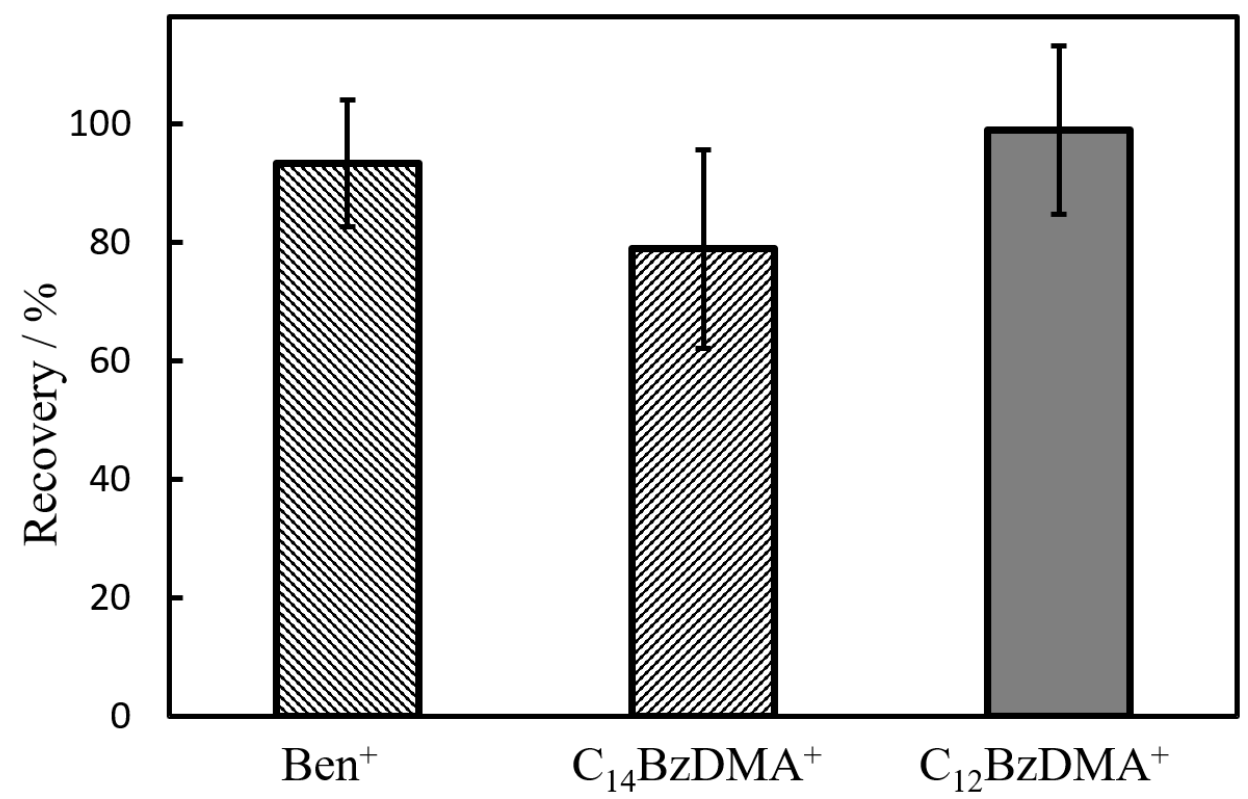

Figure 3. Testing of ion-associate phase microextraction/back-microextraction using different organic cations on the recovery of nickel. The different organic cations, Ben ${ }^{+}$: Benzethonium ion, $\mathrm{C}_{14} \mathrm{BzDMA}^{+}$: benzyldimethyltetradecylammonium ion, $\mathrm{C}_{12} \mathrm{BzDMA}^{+}$: benzyldodecyldimethylammonium ion, error bars; the relative standard deviation of the absorbance obtained in the first extraction, no. of replicates; 3 , concentration factor; $400,\left[\mathrm{Ni}^{2+}\right] ; 1.0 \mu \mathrm{g} \mathrm{L}-1$.

By adding $\mathrm{C}_{12} \mathrm{BzDMA}^{+}$, the IAP was formed by Equations (5)-(7),

$$
\begin{gathered}
\mathrm{mTTA}^{-}+\mathrm{mC}_{12} \mathrm{BzDMA}^{+} \rightleftharpoons\left\{\left(\mathrm{C}_{12} \mathrm{BzDMA}^{+} \mathrm{TTA}^{-}\right)_{\mathrm{m}}\right\}_{\text {iap }} \\
\mathrm{nPS}^{-}+n \mathrm{C}_{12} \mathrm{BzDMA}^{+} \rightleftharpoons\left\{\left(\mathrm{C}_{12} \mathrm{BzDMA}^{+} \mathrm{PS}^{-}\right)_{n}\right\}_{\text {iap }}
\end{gathered}
$$




$$
\mathrm{HTTA} \rightleftharpoons \mathrm{HTTA}_{\text {iap }}
$$

where subscript iap refers to the IAP.

The quantity of $0.1 \mathrm{M} \mathrm{C}_{12} \mathrm{BzDMA}^{+}$solution added as a $\mathrm{Q}^{+}$, a constituent of the IAP, was determined (Figure 4 ). When the quantity of $0.1 \mathrm{M} \mathrm{C}_{12} \mathrm{BzDMA}^{+}$solution added was $0.3-0.5 \mathrm{~mL}$, the recovery of nickel was the highest. Thus, the optimal quantity of added $\mathrm{Q}^{+}$ was $0.4 \mathrm{~mL}$.

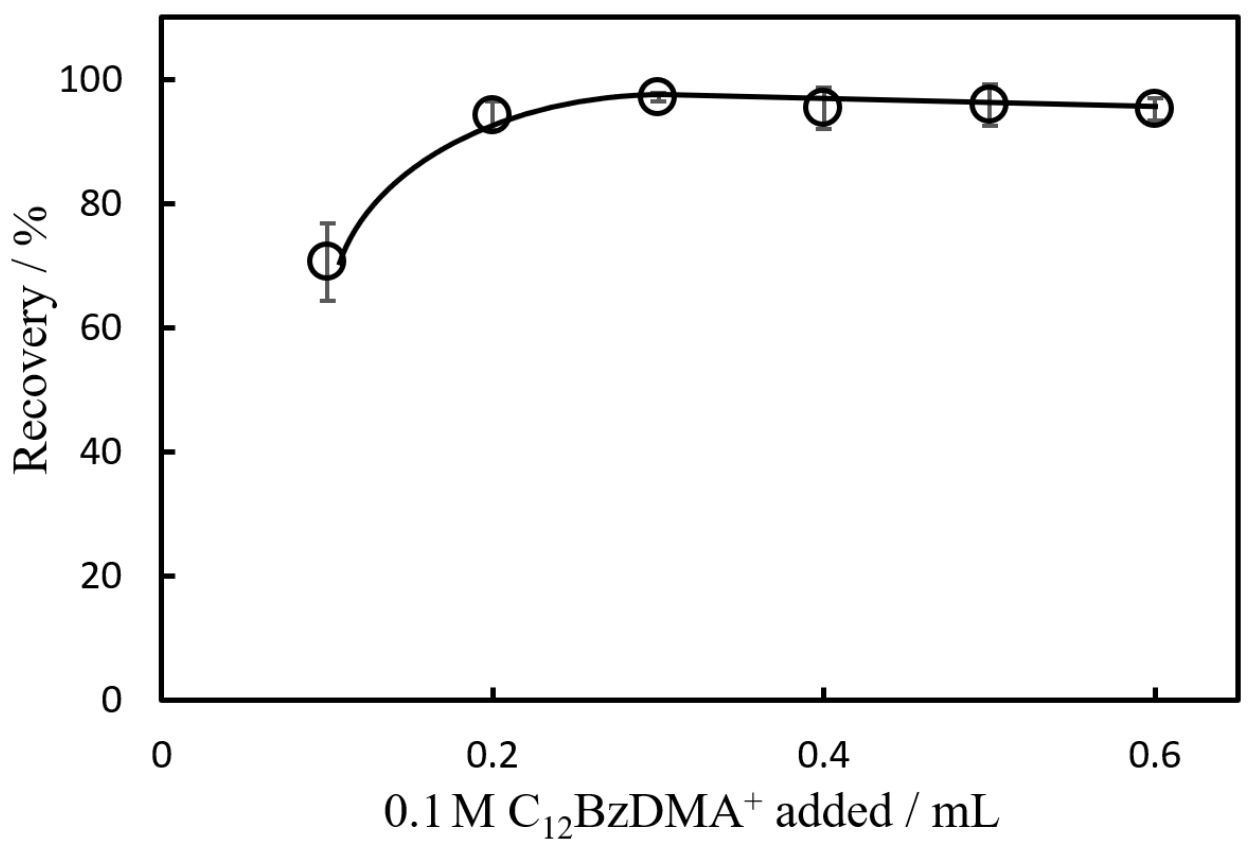

Figure 4. Effect of the amount of $0.1 \mathrm{M} \mathrm{C}_{12} \mathrm{BzDMA}^{+}$solution added on the recovery of nickel, concentration factor; $400,\left[\mathrm{Ni}^{2+}\right] ; 1.0 \mu \mathrm{g} \mathrm{L}^{-1}$.

$\mathrm{TTA}^{-}$forms a valence-saturated chelate, $\mathrm{Ni}(\mathrm{TTA})_{2} \cdot 2 \mathrm{H}_{2} \mathrm{O}$, with nickel(I1) but this chelate cannot be extracted into inert solvents such as 1,2-dichloroethane unless there is a synergistic effect [22,26]. However, Noriki reported that in the presence of quaternary ammonium ions $\left(\mathrm{Q}^{+}\right)$such as $\mathrm{C}_{14} \mathrm{BzDMA}^{+}$, the nickel(II)-TTA chelate can be extracted into 1,2-dichloroethane as $\left[\mathrm{Ni}(\mathrm{TTA})_{3}\right]^{-} \cdot \mathrm{Q}^{+}[22,26]$. Sekine et al. reported that tetrabutylammonium ion $\left(\mathrm{tba}^{+}\right)$enhanced the extraction of Ni-TTA complex into chloroform by forming ternary complex, $\left[\mathrm{Ni}(\mathrm{TTA})_{3}\right]^{-} \cdot \mathrm{tba}^{+}[22]$. These suggest that nickel is extracted in the form of $\mathrm{C}_{12} \mathrm{BzDMA}^{+} \cdot\left[\mathrm{Ni}(\mathrm{TTA})_{3}\right]^{-}$rather than $\mathrm{Ni}(\mathrm{TTA})_{2}$ in this IAP microextraction system and that $\mathrm{C}_{12} \mathrm{BzDMA}^{+}$is not only a constituent of IAP, but also facilitates the extraction of Ni-TTA complex. The Ni-TTA chelate is extracted into IAP as follows.

$$
\begin{gathered}
\left(\mathrm{C}_{12} \mathrm{BzDMA}^{+}\left[\mathrm{Ni}(\mathrm{TTA})_{3}\right]^{-}\right) \rightleftharpoons\left(\mathrm{C}_{12} \mathrm{BzDMA}^{+}\left[\mathrm{Ni}(\mathrm{TTA})_{3}\right]^{-}\right)_{\text {iap }} \\
\text { or } \\
\left(\mathrm{C}_{12} \mathrm{BzDMA}^{+} \mathrm{TTA}^{-}\right)+\left[\mathrm{Ni}(\mathrm{TTA})_{2}\right] \rightleftharpoons\left(\mathrm{C}_{12} \mathrm{BzDMA}^{+}\left[\mathrm{Ni}(\mathrm{TTA})_{3}\right]^{-}\right)_{\text {iap }}
\end{gathered}
$$

Nickel chelates with TTA ${ }^{-}$; the addition of $\mathrm{C}_{12} \mathrm{BzDMA}^{+}$causes the formation of an ion associate with $\mathrm{TTA}^{-}$and the extraction of the $\mathrm{Ni}^{-} \mathrm{TTA}^{-}$complex into the IAP. When nitric acid is added, nickel is extracted into the nitric acid phase by reverse microextraction.

The illustration of IAP microextraction/back-microextraction system for nickel in the proposed system were shown in Figure 5. When TTA ${ }^{-}$and PS $^{-}$are added, the Ni-TTA complex is formed, then when $\mathrm{C}_{12} \mathrm{BzDMA}^{+}$is added, IAP is formed and the Ni complex is extracted into the IAP. 


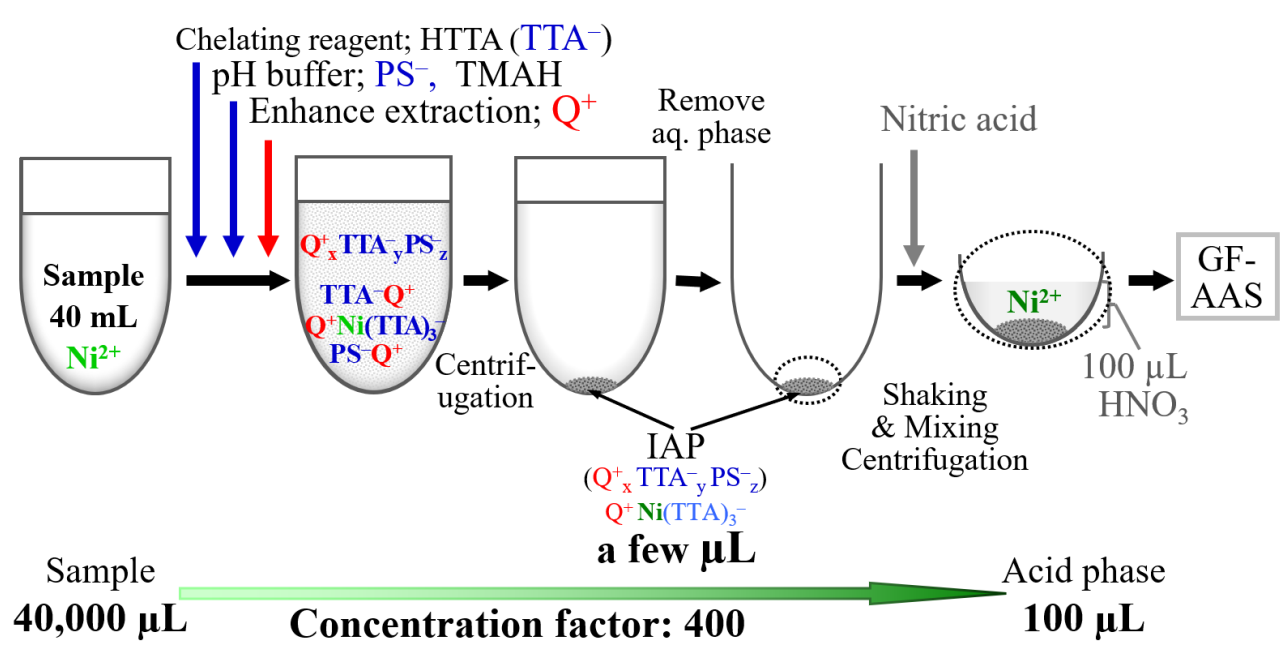

Figure 5. Illustration of the IAP microextraction and back-microextraction system for nickel in the proposed method. IAP: ion associate phase, $\mathrm{Q}^{+}$: benzyldodecyldimethylammonium ion $\left(\mathrm{C}_{12} \mathrm{BzDMA}^{+}\right)$, HTTA: thenoyltrifluoroacetone, TTA $^{-}$: thenoyltrifluoroacetonate ion (enol form after deprotonation), PS $^{-}$: phenolsulfonate ion, GF-AAS: graphite-furnace atomic-absorption spectroscopy, TMAH: tetramethylammonium hydroxide.

Assuming no interaction between each compound, the composition of the IAP was determined from the absorption spectrum. The results showed that TTA ${ }^{-}$and $\mathrm{PS}^{-}$were present in almost equal concentrations in the IAP before back-microextraction. In addition, thenoyltrifluoroacetone in IAP was mostly present as $\mathrm{TTA}^{-}$before back-microextraction and mostly present as HTTA after back-microextraction. To balance the charge. tetramethylammonium ion $\left(\mathrm{TMA}^{+}\right)$may also constitute the IAP. In other words, the formation of IAP is presumed to be in Equation (9), not Equations (5)-(7),

$$
\mathrm{xC}_{12} \mathrm{BzDMA}^{+}+\mathrm{mTTA}^{-}+\mathrm{nPS}^{-} \rightleftharpoons\left(\mathrm{C}_{12} \mathrm{BzDMA}^{+}{ }_{\mathrm{x}} \mathrm{TTA}^{-}{ }_{\mathrm{m}} \mathrm{PS}^{-}{ }_{n}\right)_{\text {iap }}
$$

where $\mathrm{m}$ and $n$ were approximately equal, if we assume that the interactions between compounds in the UV spectrum are negligible. The volume of the IAP was visually measured and found to be less than $10 \mu \mathrm{L}$. If the volume is less than $10 \mu \mathrm{L}$, the concentration of TTA and PS in the IAP would be more than $1 \mathrm{M}$ each. Ni was extracted into the nitric acid phase.

\subsection{Back-Microextraction}

Nickel was back-microextracted from the IAP that extracted the nickel complex into $2 \mathrm{M}$ nitric acid solution containing phosphate $(100 \mu \mathrm{L})$, and then analysed by GF-AAS. Nickel extracted into the IAP is back-microextracted into the acid solution by adding acid $(\mathrm{HX})$, as shown in the following equation.

$$
\left\{\mathrm{C}_{12} \mathrm{BzDMA}^{+} \cdot\left[\mathrm{Ni}(\mathrm{TTA})_{3}\right]^{-}\right\}+3 \mathrm{HX} \rightleftharpoons \mathrm{Ni}^{2+}+3 \mathrm{HTTA}+\mathrm{C}_{12} \mathrm{BzDMA}^{+} \cdot \mathrm{X}^{-}+2 \mathrm{X}^{-}
$$

In previous studies [19,20], nitric acid has been chosen as the acid of choice for the backextraction of metal ions from IAP. As the nitrate ion is a moderately large ion, it can extract metals quantitatively and do not form insoluble compounds with the organic cations that consist of the IAP. A nitric acid solution is the preferred solution for GF-AAS measurements. Therefore, nitric acid was chosen qua the optimal acid for back-microextraction of nickel from the IAP.

The effect of the concentration of nitric acid on the quantitative back-microextraction of nickel was investigated. The results are shown in Figure 6; with nitric acid concentrations of $1.0 \mathrm{M}$ or higher, nickel was quantitatively back-microextracted into the nitric acid phase. Therefore, we used a nitric acid concentration of $2.0 \mathrm{M}$ qua the optimal solvent for back-microextraction. 


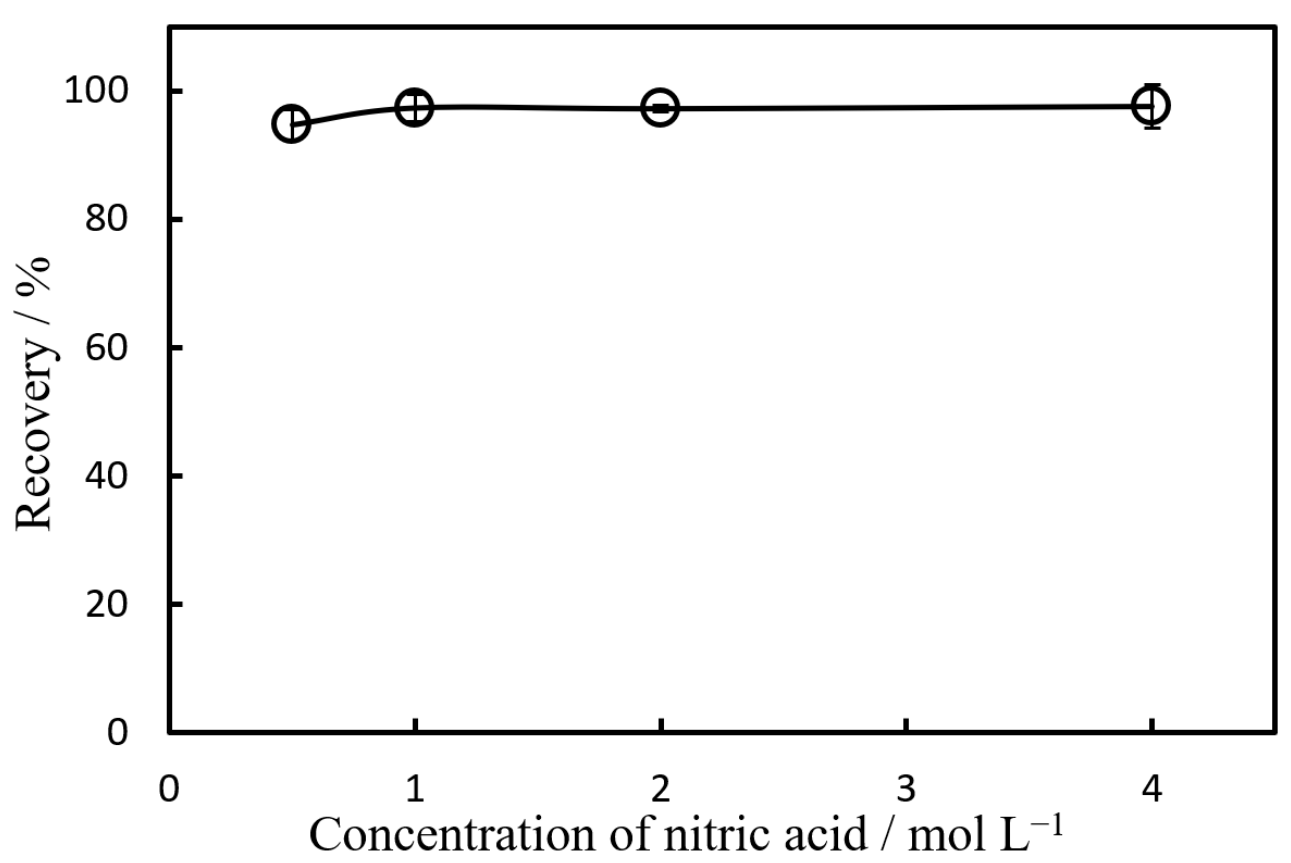

Figure 6. Effect of concentration of nitric acid for back-extraction on the recovery of nickel. The volume of acid: $100 \mu \mathrm{L}$, concentration factor; $400,\left[\mathrm{Ni}^{2+}\right] ; 1.0 \mu \mathrm{g} \mathrm{L}^{-1}$.

In the IAP microextraction, the extraction of the analyte was instantaneous because of the formation of an ion associate from the aqueous phase; thus, shaking was not necessary. In contrast, back-microextraction often required shaking to facilitate sufficient distribution quickly because of the involvement of two phases, the IAP and the nitric acid phase. In the proposed method, shaking and mixing were considered for quantitative back-extraction. The shaking time for back-extraction into the nitric acid solution was investigated (Figure 7). The maximum absorbance was obtained at a shaking time of $2-4 \mathrm{~min}$ in the test tube mixer. Shaking and mixing were chosen for 2-4 min using a test tube mixer.

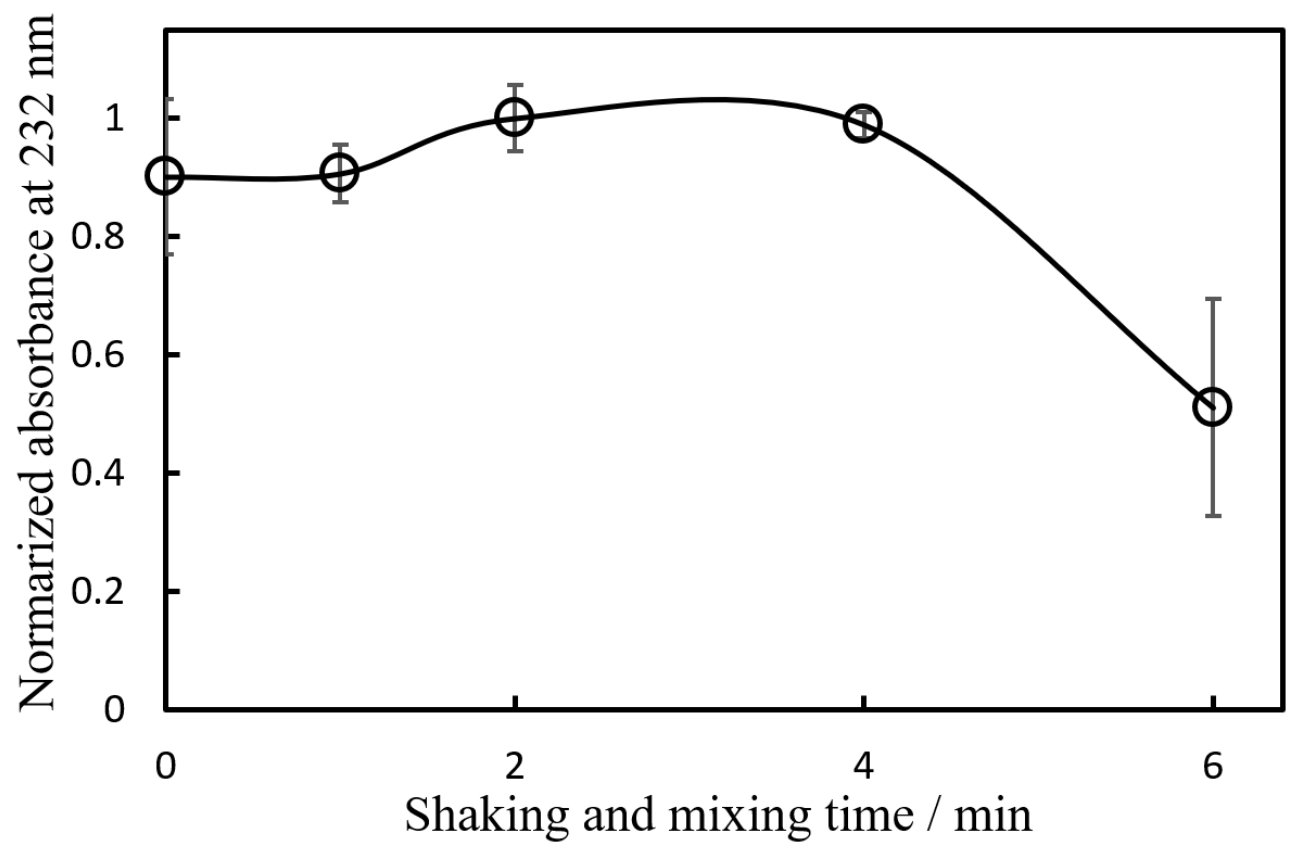

Figure 7. Effect of shaking and mixing time with the test tube mixer for acid back-microextraction. The maximum absorbance was normalized to 1 . Concentration factor; $400,\left[\mathrm{Ni}^{2+}\right] ; 1.0 \mu \mathrm{g} \mathrm{L}^{-1}$. 
The nickel-extracted IAP was treated by two methods: one was back-microextraction with acid (the proposed method), and the other was dissolution in an organic solvent (see Ref. [17]), and the results measured by GF-AAS were compared. When nickel was back-microextracted from the IAP with the nitric acid solution, the sensitivity was about 1.5 times higher than when IAP was dissolved in an organic solvent $(100 \mu \mathrm{L}$ of 2-methoxyethanol). The detection limits for the dissolution and back- microextraction methods were $0.03 \mu \mathrm{g} \mathrm{L}^{-1}$ and $0.02 \mu \mathrm{g} \mathrm{L}^{-1}$, respectively. These results indicate that the acid back-microextraction method (this method) is effective than the dissolution method by 2-methoxyethanol for GF-AAS-based determination of nickel.

\subsection{Optimized Procedure}

We placed $40 \mathrm{~mL}$ of the sample solution (acidified with $\mathrm{HNO}_{3}$ to $0.01 \mathrm{M}$ ) into a $50 \mathrm{~mL}$ plastic centrifuge tube. Next, $0.5 \mathrm{~mL}$ of $0.1 \mathrm{M}$ HTTA acetone solution was added as a chelating reagent and an $\mathrm{OA}^{-}$. Then, $2 \mathrm{~mL}$ of a p-phenolsulfonate solution $(0.5 \mathrm{M})$ was added and $\mathrm{pH} 8$ was adjusted with $12.5 \%$ TMAH solution to form a nickel complex. Subsequently, $0.4 \mathrm{~mL}$ of the $\mathrm{C}_{12} \mathrm{BzDMA}^{+}$solution $(0.1 \mathrm{M})$ was added to form the IAP and the chelating complex was extracted. The aqueous phase was then discarded after centrifugation at $4500 \mathrm{rpm}$ for $15 \mathrm{~min}$. When the amount of remaining water was reduced, the aqueous phase was aspirated with a syringe.

Next, $100 \mu \mathrm{L}$ of $2 \mathrm{M}$ nitric acid solution containing ammonium dihydrogen phosphate was added to the IAP after the extraction of the nickel chelate to back-microextract the nickel ion into the nitric acid phase (upper phase). The solution was shaken with a test tube mixer for 2-4 min and then centrifuged at $2500 \mathrm{rpm}$ for $10 \mathrm{~min}$. The concentration of nickel in the acid phase was then measured via GF-AAS.

\subsection{Analytical Figure of Merit}

The calibration graph of $\mathrm{Ni}$ by proposed method was linear with $\mathrm{R}^{2}$ values 0.9986 over the range of $0.1-2.0 \mu \mathrm{g} \mathrm{L}^{-1}$.

The sample solution was concentrated from $40 \mathrm{~mL}$ to $100 \mu \mathrm{L}$ of nitric acid solution, so the enrichment factor was 400 times. The calibration curve obtained by 400 -fold enrichment using the proposed method was compared with the calibration curve without enrichment. Comparison of the slopes of the calibration curves showed that $97 \%$ of the nickel was recovered by this IAP microextraction/back-microextraction. Based on this recovery, the actual enrichment factor was 390 times.

The limits of detection $\left(3 \sigma_{b}\right)$ and the limits of quantification $\left(10 \sigma_{b}\right)$ on two different days (5 replicates each) were $0.017 \mu \mathrm{g} \mathrm{L} \mathrm{L}^{-1}$ and $0.056 \mu \mathrm{g} \mathrm{L}-1$, and $0.031 \mu \mathrm{g} \mathrm{L}^{-1}$ and $0.10 \mu \mathrm{g} \mathrm{L}^{-1}$, respectively.

The relative standard deviation (RSD) was $4.5 \%$ at $0.1 \mu \mathrm{g} \mathrm{L}^{-1}, 7.1 \%$ at $0.5 \mu \mathrm{g} \mathrm{L}-1$, and $3.3 \%$ at $1.0 \mu \mathrm{g} \mathrm{L}^{-1}$ (3 replicates each).

\subsection{Application to River Water and Seawater Samples}

The proposed method was applied to real environmental water samples. River water was collected from the bridges closest to the mouths of the Jinzu and Joganji rivers, which flow into Toyama Bay in the Japan Sea, and seawater was collected from Toyama Bay in the Japan Sea. The acidity of all three real water samples was adjusted to $0.01 \mathrm{M}$ nitric acidity by adding $0.6 \mathrm{~mL}$ of concentrated nitric acid to $1 \mathrm{~L}$ of the sample. IAP microextraction/back-microextraction was performed according to the optimized procedure. The nickel concentrations in the water samples were $0.24 \mu \mathrm{g} \mathrm{L}^{-1}$ in the Jinzu River, $0.05 \mu \mathrm{g} \mathrm{L}^{-1}$ in the Joganji River, and $0.13 \mu \mathrm{g} \mathrm{L}^{-1}$ in the seawater, respectively. The standard addition method was performed for the river water samples and compared with the calibration curve for the standard solution without river water (Figure 8). The calibration curves obtained by adding the standard solution to the Jinzu River and the Joganji River were almost identical to the slope of the calibration curve of the standard solution. 


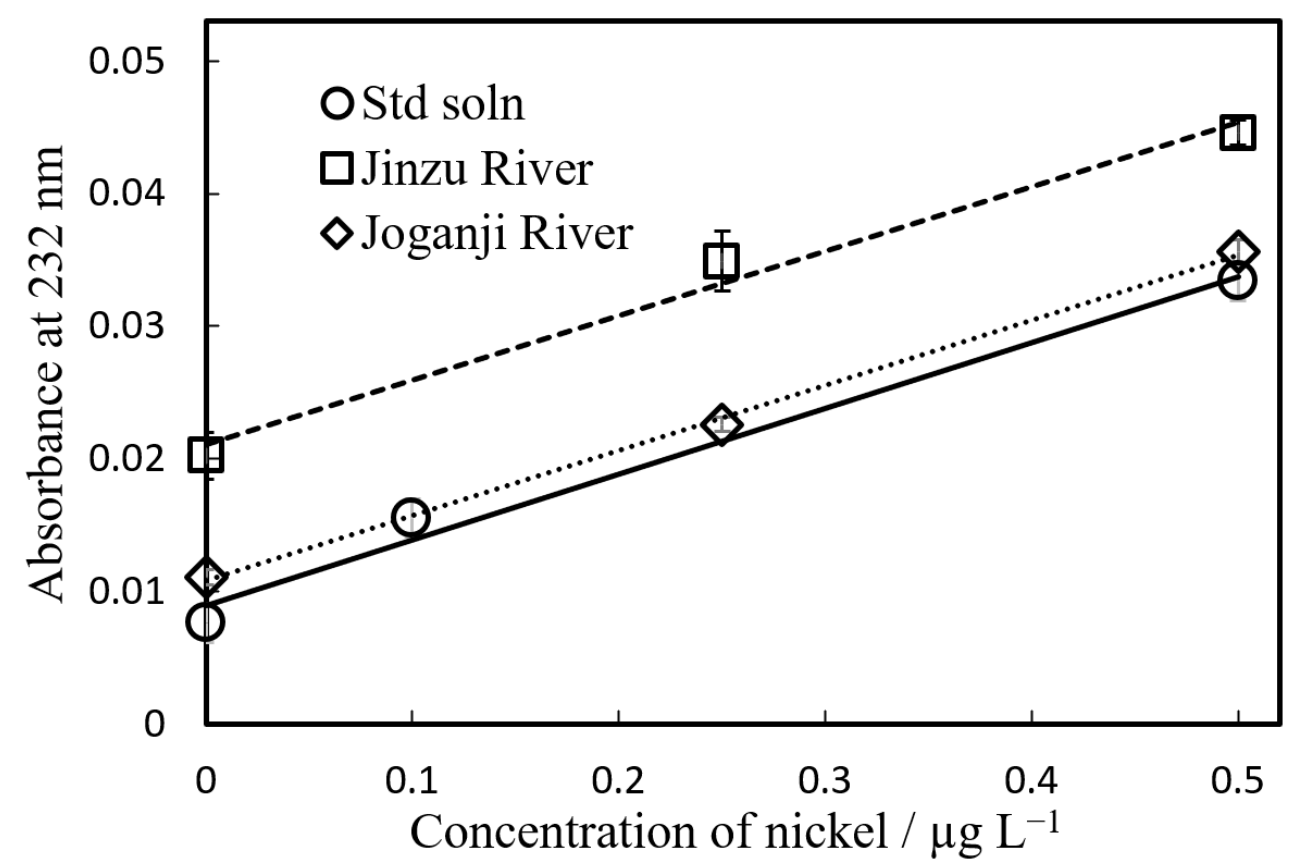

Figure 8. Standard addition of nickel for river water sample. No. of replicates; 2, concentration factor; 400. Jinzu River: the channel length: $120 \mathrm{~km}$, the population in the basin: approx. 380,000 [28]; Joganji River: the channel length: $56 \mathrm{~km}$, the population in the basin: approx. 28,000 [28].

Spike recovery tests were performed at concentrations of 0.13 and $0.25 \mu \mathrm{g} \mathrm{L}^{-1}$ using the seawater sample (Table 1). Nickel at the submicrogram per liter level could be recovered quantitatively from the seawater sample. The quantitative recovery of nickel was achieved from the Toyama Bay seawater. Moreover, nickel at the submicrogram per liter level could be recovered quantitatively from the seawater sample. Based on these results, we confirmed that nickel can be extracted effectively without being affected by the components contained in seawater.

Table 1. Nickel recovery test results for seawater sample.

\begin{tabular}{|c|c|c|c|c|c|}
\hline \multirow{2}{*}{ Sample } & \multirow{2}{*}{ Ni Added $/ \mu \mathrm{g} \mathrm{L}^{-1}$} & \multirow{2}{*}{$\begin{array}{c}\text { Ni Found } / \mu \mathrm{g} \mathrm{L}^{-1} \\
\text { Mean } \pm \mathrm{SD}^{\mathrm{a}}\end{array}$} & \multicolumn{2}{|c|}{ Recovery of Added Ni } & \multirow{2}{*}{$\begin{array}{l}\text { Number of } \\
\text { Replicates }\end{array}$} \\
\hline & & & $\mu g \mathrm{~L}^{-1}$ & $\%$ & \\
\hline \multirow[t]{3}{*}{ Toyama Bay ${ }^{b}$} & 0 & $0.13 \pm 0.02$ & - & - & 5 \\
\hline & 0.125 & $0.25 \pm 0.02$ & 0.12 & 99 & 3 \\
\hline & 0.25 & $0.37 \pm 0.03$ & 0.24 & 95 & 3 \\
\hline
\end{tabular}

${ }^{\mathrm{a}}$ mean \pm sd: mean \pm standard deviation; ${ }^{\mathrm{b}}$ More than $10 \mathrm{~km}$ offshore.

The proposed method was also applied for the detection of certified reference materials (NASS 3) in seawater. The nickel concentration in the reference sample was $0.257 \pm 0.027 \mu \mathrm{g} \mathrm{L}^{-1}$ and that detected through the proposed method was $0.244 \pm 0.014 \mu \mathrm{g} \mathrm{L}^{-1}$ (mean \pm standard deviation, number of replicates: 3 ). The nickel concentration detected by the proposed method was in good agreement with the certified value.

\section{Conclusions}

A novel system for the enrichment and separation of nickel in environmental water based on IAP microextraction/back-microextraction was developed and applied to measurements via GF-AAS. Nickel at submicrogram per liter levels was successfully detected in river water and seawater samples.

As with dipivaloylmethane for lithium [20], $\beta$-diketones chosen for this study, 2thenoyltrifluoroacetone (HTTA), were found to act not only as a chelating reagent but also 
as one of the organic anion in the IAP. In this study, $\mathrm{TTA}^{-}$and phenolsulphonate ions played a double role: $\mathrm{pH}$ buffer and one of the organic anion in the IAP. In addition, the benzyldodecyldimethylammonium ion $\left(\mathrm{C}_{12} \mathrm{BzDMA}^{+}\right)$was involved in the extraction of nickel complexes $\left(\mathrm{C}_{12} \mathrm{BzDMA}^{+} \cdot\left[\mathrm{Ni}(\mathrm{TTA})_{3}\right]^{-}\right)$as well as served as a component of the IAP, i.e., the organic cation.

Author Contributions: Conceptualization, M.K. and N.H.; methodology, M.K. and N.H.; investigation, M.K., K.M., K.S., T.O. and N.H.; resources, H.K., S.T. and N.H.; data curation, M.K. and N.H.; writing—original draft preparation, M.K. and N.H.; writing—review and editing, M.K., K.S., H.K., S.T. and N.H.; visualization, M.K. and N.H.; supervision, H.K., S.T. and N.H.; project administration, N.H.; funding acquisition, N.H. All authors have read and agreed to the published version of the manuscript.

Funding: This work was supported by the Japan Society for the Promotion of Science (JSPS) KAKENHI Grant Numbers 19K05561 and JP23615004.

Data Availability Statement: Not applicable.

Acknowledgments: We thank Northwest Pacific Region Environmental Cooperation Centre, and the National Institute of Technology, Toyama College, especially Hajime Chiba, for the opportunity to collect seawater sample.

Conflicts of Interest: The authors declare no conflict of interest.

\section{References}

1. National Astronomical Observatory of Japan. Chronological Environmental Tables 2015-2016; Maruzen Publishing: Tokyo, Japan, 2015.

2. WHO. Guidelines for Drinking-Water Quality, 4th ed.; Incorporating the 1st addendum; World Health Organization: Geneva, Switzerland, 2017; ISBN 978-92-4-154995-0.

3. The Japan Mining Promotive Foundation. Nickel. Bulletin Kozan 2020, 787, 80-93. Available online: https://j-mining-pf.jp/ bulletin-kozan / (accessed on 6 January 2021).

4. Shijo, Y.; Shimizu, T.; Tsunoda, T.; Shiquan, T.; Suzuki, M. Preconcentration of submicrogram amounts of nickel of Nickel by Liquid-Liquid-Extraction and Micro Back-Extraction from water for graphite-Furnace atomic-absorption spectrometry. Anal. Chim. Acta 1991, 242, 209-213. [CrossRef]

5. Watanabe, H.; Tanaka, H. A non-ionic surfactant as a new solvent for liquid-liquid extraction of zinc (II) with 1-(2-pyridylazo)-2naphthol. Talanta 1978, 25, 585-589. [CrossRef]

6. Han, Q.; Huo, Y.Y.; Yang, L.G.; Yang, X.H.; He, Y.P.; Wu, J.Y. Determination of Trace Nickel in Water Samples by Graphite Furnace Atomic Absorption Spectrometry after Mixed Micelle-Mediated Cloud Point Extraction. Molecules 2018, 23, 2597. [CrossRef]

7. Jiang, H.M.; Qin, Y.C.; Hu, Q. Dispersive liquid phase microextraction (DLPME) combined with graphite furnace atomic absorption spectrometry (GFAAS) for determination of trace Co and Ni in environmental water and rice samples. Talanta 2008, 74, 1160-1165. [CrossRef] [PubMed]

8. Liang, P.; Peng, L.L. Determination of Nickel in Water Samples by Graphite Furnace Atomic Absorption Spectrometry After Ionic Liquid-Based Dispersive Liquid-Liquid Microextraction Preconcentration. At. Spectrosc. 2012, 33, 53-58. [CrossRef]

9. Sorouraddin, S.M.; Nouri, S. Simultaneous temperature-assisted dispersive liquid-liquid microextraction of cobalt, copper, nickel and zinc ions from high-volume water samples and determination by graphite furnace atomic absorption spectrometry. Anal. Methods 2016, 8, 1396-1404. [CrossRef]

10. Saitoh, T.; Ohyama, T.; Sakurai, T.; Kaise, T.; Takamura, K.; Suzuki, Y.; Matsubara, C. Polymer-mediated extraction of 8quinolinolato metal chelates for the determination of metal ions in water with graphite furnace atomic absorption spectrometry. Talanta 1998, 46, 541-550. [CrossRef]

11. Saitoh, T.; Arakawa, A.; Hiraide, M. Preconcentration of Trace Metals in Water Using a Newly Designed Thermoresponsive Chelating Polymer for the Sensitive Determination by Graphite Furnace Atomic Absorption Spectrometry. Bull. Chem. Soc. Jpn. 2013, 86, 438-444. [CrossRef]

12. Takahashi, A.; Yamaguchi, H.; Igarashi, S. Homogeneous liquid-liquid extraction method for some kinds of high-valence metal ions using desferrioxamine B. Bunseki Kagaku 1997, 46, 55-58. [CrossRef]

13. Sorouraddin, S.M.; Farajzadeh, M.A.; Okhravi, T. Cyclohexylamine as extraction solvent and chelating agent in extraction and preconcentration of some heavy metals in aqueous samples based on heat-induced homogeneous liquid-liquid extraction. Talanta 2017, 175, 359-365. [CrossRef] [PubMed]

14. Habibiyan, A.; Ezoddin, M.; Lamei, N.; Abdi, K.; Amini, M.; Ghazi-khansari, M. Ultrasonic assisted switchable solvent based on liquid phase microextraction combined with micro sample injection flame atomic absorption spectrometry for determination of some heavy metals in water, urine and tea infusion samples. J. Mol. Liq. 2017, 242, 492-496. [CrossRef] 
15. Hata, N.; Kasahara, I.; Taguchi, S. Micro-phase sorbent extraction for trace analysis via in situ sorbent formation: Application to the preconcentration and the spectrophotometric determination of trace ammonia. Anal. Sci. 2002, 18, 697-699. [CrossRef] [PubMed]

16. Hata, N.; Yuwatini, E.; Ando, K.; Yamada, M.; Kasahara, I.; Taguchi, S. Micro-organic ion-associate phase extraction via in situ fresh phase formation for the preconcentration and determination of di(2-ethylhexyl)phthalate in river water by HPLC. Anal. Sci. 2004, 20, 149-152. [CrossRef]

17. Hata, N.; Hieda, S.; Yamada, M.; Yasui, R.; Kuramitz, H.; Taguch, S. Formation of a liquid organic ion associate in aqueous solution and its application to the GF-AAS determination of trace cadmium in environmental water as a complex with 2-(5bromo-2-pyridylazo)5-(N-propyl-N-sulfopropylamino)phenol. Anal. Sci. 2008, 24, 925-928. [CrossRef]

18. Nakayama, K.; Yamamoto, T.; Hata, N.; Taguchi, S.; Takamura, Y. Liquid Electrode Plasma Atomic Emission Spectrometry Combined with Multi-Element Concentration Using Liquid Organic Ion Associate Extraction for Simultaneous Determination of Trace Metals in Water. Bunseki Kagaku 2012, 60, 515-520. [CrossRef]

19. Noor, S.M.A.; Murashima, R.; Okazaki, T.; Taguchi, S.; Kuramitz, H.; Hata, N. Micro-organic Ion-associate Phase Extraction/microvolume Back-extraction for the Preconcentration and GF-AAS Determination of Cadmium, Nickel and Lead in Environmental Water. Anal. Sci. 2018, 34, 1445-1448. [CrossRef]

20. Mizuna, K.; Murashima, R.; Okazaki, T.; Sazawa, K.; Kuramitz, H.; Taguchi, S.; Nakayama, K.; Yamamoto, T.; Takamura, Y.; Hata, N. Organic Ion-associate Phase Extraction/Back-microextraction for the Preconcentration and Determination of Lithium Using 2,2,6,6-Tetramethyl-3,5-heptanedione by Liquid Electrode Plasma Atomic Emission Spectrometry and GF-AAS in Environmental Water. Anal. Sci. 2020, 36, 595-600. [CrossRef] [PubMed]

21. Taguchi, S.; Asaoka, M.; Hirokami, E.; Hata, N.; Kuramitz, H.; Kawakami, T.; Miyatake, R. A simple and rapid method for simultaneous pre-concentration of eight trace-heavy-metals in water using 1-(2-pyridylazo)-2-naphthol and yttrium for X-ray fluorescence spectrometry. Anal. Methods 2015, 7, 6545-6551. [CrossRef]

22. Noriki, S. Effects of quaternary ammonium bases on valence-saturated but coordination-unsaturated chelates: Part III. Extraction of nickel- and cobalt-thenoyltrifluoro-acetone chelates. Anal. Chim. Acta 1975, 215, 215-218. [CrossRef]

23. Sekine, T.; Nguyen, T.K.D.; Noro, J. Solvent-Extraction of Several Divalent Metal-Ions with Benzoyltrifluoroacetone and 2Thenoyltrifluoroacetone into Chloroform in the Presence of Tetrabutylammonium Ions. Bull. Chem. Soc. Jpn. 1994, 67, $432-437$. [CrossRef]

24. Nakao, M.; Matsumiya, H.; Hiraide, M. Simultaneous separation of traces of cobalt, nickel, and copper from an aluminum matrix with an emulsion containing mixed ligands for graphite-furnace atomic absorption spectrometry. Bunseki Kagaku 2004, 53, 975-980. [CrossRef]

25. Kidani, K.; Imura, H. Talanta Solvent effect of ionic liquids on the distribution constant of 2-thenoyltrifluoroacetone and its nickel(II) and copper(II) chelates and the evaluation of the solvent properties based on the regular solution theory. Talanta 2010, 83, 299. [CrossRef] [PubMed]

26. Ueno, K.; Imamura, T. $\beta$-Diketones. In Handbook of Organic Analytical Reagents, 2nd ed.; Ueno, K., Imamura, T., Cheng, K.L., Eds.; CRC Press: Boca Raton, FL, USA, 1992.

27. The Chemical Society of Japan. Acid Dissociation Constants of Organic Acids and Bases. In Kagaku Binran (Handbook of Chemistry) Basic, 6th ed.; Maruzen Publishing: Tokyo, Japan, 2021. (In Japanese)

28. Rivers in Hokuriku, Japan, Prepared by Ministry of Land, Infrastructure, Transport and Tourism, Japan. Available online: https:/ / www.mlit.go.jp/river/toukei_chousa/kasen/jiten/nihon_kawa/04_hokuriku.html (accessed on 8 October 2021). 